\title{
Does Inflation Reduce Air Pollution? Evidence from Indonesia
}

\author{
Andryan Setyadharma ${ }^{1}{ }^{1}$, Shanty Oktavilia $^{1}$, Indah Fajarini Sri Wahyuningrum ${ }^{1}$, Sri \\ Indah Nikensari ${ }^{2}$ and Arumawan Mei Saputra ${ }^{1}$ \\ ${ }^{1}$ Faculty of Economics, Universitas Negeri Semarang, Semarang, Indonesia \\ ${ }^{2}$ Faculty of Economics, Universitas Negeri Jakarta, Jakarta, Indonesia
}

\begin{abstract}
Inflation could likely cause devastating impacts where high inflation can harmful economic and social circumstances. However, only limited studies try to find the impact of inflation on the quality of air. The aim of this study is to investigate the empirical linkage between inflation and air pollution in Indonesia covering the period of 1981 until 2017 by using an error correction model (ECM) methodological approach. The result of study suggests that in the short run, higher inflation is causing the lower level of air pollution. Similarly, in the long run, higher inflation is also affecting the lower level of air pollution. While there are a lot of negative impacts of inflation in Indonesia, the finding in this study indicates a positive impact of inflation in Indonesia, which is higher inflation can reduce the air pollution. The results seem contradict with the target of central bank of Indonesia to have a low but positive rate of inflation. Based on the findings, the study suggests the policymakers in Indonesia to support a robust role of inflation stability in achieving targets related to the reduction of air pollution.
\end{abstract}

\section{Introduction}

Indonesia has experienced steady economic growth since the end of the 1998 Asian financial crisis, with the average economic growth are more than $5 \%$ per year. Indonesia has also successfully raised per capita income, reduced poverty, and increased living standards. Indonesia's economic success stories, however, have come with environmental problems. Since natural resources are the main contributors to Indonesia's economic growth, they put more pressure on the environment. The non-environmentally friendly economic activities, such as deforestation and excessive fossil fuels usage, have made Indonesia one of the primary greenhouse gas contributors in the world [1].

\footnotetext{
* Corresponding author: andryan@mail.unnes.ac.id
} 
However, the greenhouse gas emissions problems are not new issues. The rapid increase in greenhouse gas emissions has become one of the world's leading problems in the last few decades. This has put the awareness of governments, institutions, and researchers to investigate the main contributors of pollution emissions at the macro and micro levels [2 \& 3]. Previous studies have acknowledged that economic activities lead to pollution emissions and put various variables such as energy consumption, production, trade, export-import, industrialization, investment, urbanization, and others to find the relationship between these variables and environmental degradation. In addition, some studies also find that macroeconomic variables are the crucial contributors to the environment. Degradation. It is believed that macroeconomic instability contributes to a specific impact on pollution emissions [4]. A country is classified under macroeconomic instability when the country suffers from significant current account deficits, problems with high levels of public debt, galloping or high inflation rates, and stagnant or falling gross domestic product [5].

This study focuses on the impact of inflation on air pollution as one of the proxies of macroeconomic instability. Overall, inflation makes the economic activities slow-moving and subsequently, relaxing the pressure on the environment. There are only a few studies on the inflation-environmental quality nexus. Previous studies rarely highlight the issue of how inflation influences the quality of the environment. Therefore, this study offers new knowledge to the existing literature by being the first study investigating the impact of inflation on the quality of air in the Indonesian economy. This study is essential because Indonesia is one of the key players in dealing with climate change problems. Indonesia is one of the world's most significant greenhouse gas contributors, and the country must cut its emissions at least $29 \%$ by 2030 [1].

Humans are believed as the main suspect of the degradation of the environment [6]. Their economic activities have been responsible for the low quality of the environmental conditions. The change in inflation that leads to slow economic activities can be explained by the demand and supply of goods and services. In both demand and supply, inflation diminishes the effectiveness of the price mechanism. On the demand side, the higher demand for the goods or services will lead to higher prices or inflation. For example, when consumers are aware that prices will rise in the future, they will overreact by making purchases sooner, which enhances economic activities.

In addition, fiscal and monetary policies are mainly used to influence economic activity to reverse the impact of income, unemployment, and inflation [7]. The expansionary monetary or fiscal policies will increase consumers' purchasing power, leading to vibrant economic activities. However, this high consumption level will create high inflation and negatively affect future consumption spending activities. The high cost of inflation is a reduction in the purchasing power of consumers, as the result of reduction of real income, and as a result, slowing down the economic activities. Thus, the pressure on the environment is reduced, and environmental quality is getting better. In general, inflation disturbs the aggregate demand, but it has resulted in better environmental quality.

On the supply side, the effect of inflation on production appears when the inflation is cost-push inflation. When the cost of inputs of production increases, there will be a drop in the total productivity level as the rise in production cost will disturb the production budget of the producers. Furthermore, the rising cost of 
production will be transferred to the consumers by bearing higher prices [8], which will reduce consumers' aggregate demand. Inflation also delays investment projects by producers, and the consequence is a reduction in productivity [ $2 \& 9]$. So, in this case, inflation will slow down producers' economic activities, which may support the protection of the environment. In conclusion, inflation deteriorates the overall economic performance in demand and supply, but it helps the environment.

Limited previous studies have shown a mixed and inconclusive relationship between inflation and environmental quality. The empirical finding by [2] shows that higher inflation instability reduces environmental pollution. [2] argue that higher prices create economic uncertainty that prevents investment plans and spending, thus enhancing environmental quality. [9] find that inflation contributes to a decline in environmental degradation. However, the coefficient of the inflation variable in their study is closer to zero, indicating almost no effect of inflation on $\mathrm{CO}_{2}$ emissions. A study by [10] also confirms the negative relationship between inflation and environmental quality. Using the autoregressive distributed lag (ARDL) approach, the long-run result indicates that a reduction in inflation instability causes higher $\mathrm{CO}_{2}$. They argue that in a low inflation zone, consumers tend to engage in more economic activities that increase $\mathrm{CO}_{2}$ emissions. Based on their research, [10] conclude that the low inflation rate has become a central problem to a better quality of the environment in Pakistan. However, in contrast, a study by [4] does not support [10] empirical results. Although both studies were conducted in Pakistan and applied a similar ARDL method, [4] shows a different result. [4] the finding supports a positive relationship between inflation as a proxy of macroeconomic uncertainty and $\mathrm{CO}_{2}$ emissions, which suggests inflation uncertainty is damaging the environmental quality in Pakistan. One of the possible reasons for these contrasting results is specification error problems due to the omission of the critical variables in the model (for a detailed explanation, see $[11 \&$ 12]).

As can be inferred from the previous studies, inflation influences the quality of the environment in an antagonistic relationship and a positive relationship. Authors only found limited literature on this matter. Since the results are mixed and indecisive, this motivates us to find out the impact of inflation on $\mathrm{CO}_{2}$ emission in the case of Indonesia. Since the deterioration of the environment remains expanding, analyzing the impacts of inflation on environmental quality is crucial. As there are only limited studies in the inflation-air pollution relationship, this paper significantly contributes to the current literature. To the best of our knowledge. this study offers new empirical evidence in the literature.

\section{Research Method}

In order to establish the relationship between inflation and air pollution in Indonesia, this study uses econometric techniques, i.e., Engle-Granger Error Correction Model (E-G ECM). The E-G ECM is employed for the analysis since the model provides complete information on the dynamic short-run dan long-run connections among the cointegrating variables. The basic model, or the long-run model, is formulated as follow:

$\log (\mathrm{EM})_{\mathrm{t}}=\beta_{\mathrm{o}}+\beta_{1} \log (\mathrm{CPI})_{\mathrm{t}}+\beta_{(1)} \log (\text { ELECTRIC })_{\mathrm{t}}+\beta_{3}$ FUEL $_{\mathrm{t}}+e_{\mathrm{t}}$ 
Next, the basic model is transformed into Error Correction Model form, or the short run model, as follow:

$\mathrm{D}(\log (\mathrm{EM}))_{\mathrm{t}}=\alpha_{\mathrm{o}}+\alpha_{1} \mathrm{D}(\log (\mathrm{CPI}))_{\mathrm{t}}+\alpha_{2} \mathrm{D}(\log (\text { ELECTRIC }))_{\mathrm{t}}+\alpha_{3} \mathrm{D}(\mathrm{FUEL})_{\mathrm{t}}+\alpha_{4}$ $\mathrm{ECT}_{\mathrm{t}-1}+\varepsilon_{\mathrm{t}} \ldots \ldots \ldots \ldots \ldots{ }^{(2)}$

Where Log represents the logarithm function, EMI is $\mathrm{CO}_{2}$ emissions (metric tons per capita), CPI is consumer price index $(2010=100)$ as the proxy of inflation, ELECTRIC is electric power consumption (kWh per capita), FUEL is fuel imports ( $\%$ of merchandise imports), $e$ and $\varepsilon$ are the residuals, $t$ is the time. $\beta$ o, $\beta 1, \beta 2, \beta 3$ are the parameters for the extended run model, $\alpha 0, \alpha 1, \alpha 2, \alpha 3, \alpha 4$ are the parameters for the ECM, D is the difference between the Nt observation and Nt-1 observation.

The conditions of the E-G ECM are (1) all variables are not stationary at level, $\mathrm{I}(0)$; (2) all variables are stationary at the first difference, I(1); (3) all variables should be cointegrated. The static tests are conducted using Augmented DickeyFuller (ADF) unit root tests, and the cointegration test is conducted using the EngleGranger Cointegration test for the residuals. The Engle and Granger cointegration test is performed by running the basic model using OLS. Then, the residual in the estimated equation is stationary at level or not by using the ADF test. Suppose the residuals are stationary at level $\mathrm{I}(0)$. In that case, it indicates that the variables in the model are cointegrated. All variables in the model have a long-run or long-run equilibrium relationship between the variables in the model. If these three conditions are fulfilled, ECM analysis can be used.

\section{Results and Discussion}

The unit root tests using Augmented Dickey-Fuller indicate that all variables are not stationary at level, as all the probability values of all variables are more than $10 \%$ (or 0.10). In addition, the unit root tests using Augmented Dickey-Fuller indicate all variables are stationary at the first difference, as all the probability values of all variables are less than $10 \%$ (or 0.10 ), as seen in table 1 . The results indicate that it fulfilled the first two conditions of E-G ECM.

Table 1. Unit Root Test for Level and $1^{\text {st }}$ Difference.

\begin{tabular}{|c|c|c|}
\hline Variables & $\begin{array}{l}\text { Unit root tests in } \\
\text { Level }\end{array}$ & $\begin{array}{l}\text { Unit root tests in } 1^{\text {st }} \\
\text { Difference }\end{array}$ \\
\hline $\log (E M)$ & 0.5692 & 0.0000 \\
\hline $\log (\mathrm{CPI})$ & 0.3052 & 0.0000 \\
\hline Log (ELECTRIC) & 0.9864 & 0.0019 \\
\hline FUEL & 0.2667 & 0.0001 \\
\hline
\end{tabular}

The next step is to check the cointegration test. The test shows that the residuals are stationary at level I (0), as seen in Table 2 . The test indicates that all variables in the model are cointegrated, which means that the model has a long-run relationship. The result suggests that the model fulfilled the third condition of E-G ECM, and we can proceed to E-G ECM.

Table 2. Cointegration Test. 


\begin{tabular}{|l|c|l|c|c|}
\hline & & & t-Statistic & Prob.* \\
\hline Augmented Dickey-Fuller test statistic & & & \\
\hline Test critical values: & $1 \%$ level & & -3.281938 & 0.0017 \\
\hline
\end{tabular}

*MacKinnon (1996) one-sided p-values.

Table 3 presents the result of the short run of E-G ECM. The result in table 3 shows that the parameter of CPI has a negative and significant impact on EM. This output implies that, in the short run, if the inflation (CPI) rises by $1 \%$, the emission per capita (EM) declines by $0,06 \%$, assuming that other variables are equal, or ceteris paribus. This result implies that in the short run, high inflation creates adverse effects on current consumption spending and immediately slows down producers' production activities, which may lower the aggressive economic activities that help reduce the destruction to the environment. Based on the result, it is concluded that in the short run, high inflation reduces the overall economic performance in demand and supply, reducing the pressure on the environment. In addition, this study also uses two variables to represent energy consumption. However, these two variables are not statistically significant in the short run. The coefficient of ECT shows the speed of adjustment toward equilibrium and negative sign, and statistically significant implies a convergence from short run to long run. The speed is 0.4406 means that $44.06 \%$ of this disequilibrium is corrected between 1 year.

Table 3. Result of Short Run ECM.

\begin{tabular}{|l|l|}
\hline $\begin{array}{l}\text { Explained Variable: } \\
\text { D(Log of } \mathbf{C O}_{2} \text { Emission (EM)) }\end{array}$ \\
\hline D(LOG (CPI)) & -0.0566 \\
$(-2.349)^{* * *}$ \\
\hline DLOG (ELECTRIC) & $\begin{array}{l}0.3735 \\
(1.030)\end{array}$ \\
\hline D(LOG (FUEL)) & $\begin{array}{l}0.0022 \\
(0.496)\end{array}$ \\
\hline ECT $_{\mathrm{t}-1}$ & -0.4406 \\
$(-3.048)^{* * *}$ \\
\hline Constant & -0.0014 \\
$(-0.045)$ \\
\hline Adjusted $\mathrm{R}^{2}$ & 0.280 \\
\hline
\end{tabular}

Note: $* * *$ significance at $\mathrm{p}$-value $\leq 0.01 ; \mathrm{t}$-statistics are stated in parentheses.

Table 4 represents the result of the long run of E-G ECM. The result in table 4 shows that the parameter of CPI has a negative and significant impact on EM. This output implies that, in the long run, if the inflation (CPI) rises by $1 \%$, the $\mathrm{CO}_{2}$ emission (EM) declines by $0,073 \%$, assuming that other variables are equal, or ceteris paribus. This result indicates that high inflation generates adverse effects 
on future consumption spending in the long run because consumers start to reschedule their consumption planning in the future. It affects producers' economic activities by reducing their production planning and delaying investment projects, which create a significant drop in productivity (as suggested by [2 \& 9]). Thus, the economy is slowing down, and it helps to increase the sustainability of the environment. Based on the result, it is concluded that in the long run, high inflation again further reduces the overall economic performance in demand and supply, reducing the pressure on the environment.

Table 4. Result of Long Run ECM.

\begin{tabular}{|c|c|}
\hline \multicolumn{2}{|c|}{$\begin{array}{l}\text { Explained Variable: } \\
\text { Log of } \mathrm{CO}_{2} \text { Emission (EM) }\end{array}$} \\
\hline LOG (CPI) & $\begin{array}{l}-0.0727 \\
(-2.195) * *\end{array}$ \\
\hline DLOG (ELECTRIC) & $\begin{array}{l}0.4078 \\
(16.625)^{* * *}\end{array}$ \\
\hline LOG (FUEL) & $\begin{array}{l}0.0052 \\
(1.862)^{*}\end{array}$ \\
\hline Constant & $\begin{array}{l}-2.0483 \\
(-15.819)^{* * *}\end{array}$ \\
\hline Adjusted $\mathrm{R}^{2}$ & 0.280 \\
\hline
\end{tabular}

Note: $* * *$ significance at $\mathrm{p}$-value $\leq 0.01 ; * *$ significance at $\mathrm{p}$-value $\leq 0.05$;

$*$ significance at $\mathrm{p}$-value $\leq 0.10$. $\mathrm{t}$-statistics are stated in parentheses.

Two variables are employed as the representation of energy consumption. This result indicates that in the long run, if when electric power consumption increases by $1 \%$, the $\mathrm{CO}_{2}$ emission increases by $0.41 \%$, other with assumption variables being equal. Electric power can affect the environment; it starts when electricity is generated using fossil material that can create emissions of greenhouse gases and other air pollutants. Indonesia still relies on coal-fired power plants to produce electricity and aims to produce $23 \%$ of its energy from renewable sources in 2025 . Finally, if the percentage of imported fuel rises by $1 \%$, the emission per capita increases by $0.005 \%$, other variables being equal. Indonesia has an energy consumption problem, where the country cannot meet all domestic consumption demand, so the country must import fuel from overseas. When the country increases the fuel import, it starts to hurt the environment.

In the case of Indonesia, the study shows that a higher inflation rate will reduce $\mathrm{CO}_{2}$ emissions. This study supports previous studies by [2] and [9] that a higher inflation rate contributes to a decline in environmental degradation. [2] suggest some reasons to support the results. Firstly, they argue that a higher level of inflation influences aggregate demand, as a higher inflation rate badly impacts people who are holding money. Secondly, they suggest that the higher level of inflation rate reduces the willingness to invest. Thirdly, they indicate that a higher level of inflation rate diminishes the current demand for goods and future investment planning. Overall, all these factors reduce the economic activities then it enhances the overall environmental quality. Similarly, in the case of Indonesia, the 
higher level of inflation increases the opportunity of holding money and causes a reduction in the aggregate demand due to low consumers' purchasing power. It also disables the ability of producers to invest in the future. Whenever there is a significant rise in the inflation rate, the central bank of Indonesia usually increases its interest rate so people will send their money to the banks. It slows the economic activities, and in the end, the environment gets better.

Although this study shows that a higher inflation rate is associated with a lower level of $\mathrm{CO}_{2}$ emission, the protection of the environment through the inflation channel seems complicated because the target of the central bank of Indonesia is to have a low but positive rate of inflation. It seems to contradict because the preservation of the environment is not in line with the target of the central bank of Indonesia. The central bank of Indonesia prefers to have a low level of inflation to stabilize the Indonesian economy. However, since better environmental performance is preferable for the sake of future generations, it is suggested to the policymakers in Indonesia to support a vital role of inflation stability in achieving targets related to the reduction of air pollution by increasing the inflation target up to the level that is not harming the economy.

\section{Conclusion}

The result describes that inflation plays a crucial role in enhancing environmental conditions. This study shows that higher inflation contributes to a decline in environmental degradation. However, low and stable inflation is preferable by the Central Bank of Indonesia. Therefore, this study has some important policy implications for Indonesia's economy. The Government and the Central Bank of Indonesia should know that low and stable inflation is not suitable for the protection of the environment, so the policymakers in Indonesia should play a vital role in inflation stability that carefully consider the reduction of air pollution by increasing the inflation target up to the level that is not harming the economy.

This study also finds that in the long run, electric power consumption increases $\mathrm{CO}_{2}$ emissions. Since the electricity in Indonesia is mainly generated using fossil material, it creates more pollutants in the air. In addition, this study also reveals the positive relationship between imported fuel and $\mathrm{CO}_{2}$ emission. Undeniably, Indonesia has an energy consumption problem and is highly dependent on imported fuel. As the country rises the fuel import, it starts to hurt the environment. Therefore, Indonesia must start imposing stricter regulations about energy-efficient, applying green energy technologies. Moreover, it is also essential to have a renewable source of energy other than fossil energy.

\section{References}

1. OECD, Green Growth Policy Review of Indonesia (2019).

2. W. Ahmad, S. Ullah, I. Ozturks, M.T. Majeed, Energy \& Envir. 0, 1-17 (2020)

3. U. Al-mulali, C.F Tang, I. Ozturk, Environ Sci Pollut Res Int 22. 14891-14900 (2015)

4. M. Khan, Environ Sci Pollut Res Int; 26, 14649-14659 (2019) 
5. B. Ames, W. Brown, S. Devarajan, A. Izquierdo, PRSP Sourcebook Chapter 6, (2001)

6. M. P. Choudhary, G. S. Chauhan, Y. K. Kushwah, National Seminar on Recent Advancements in Protection of Environment and Its Management Issues (NSRAPEM-2015), Maharishi Arvind College of Engineering and Technology, Kota, Rajasthan, India (2015)

7. Congressional Research Service, Fiscal Policy: Economic Effects (2021)

8. Z. H. Javed, M. Farooq, S. Akram, J. of Econ and Inter Fin, 12, 308-312 (2010)

9. A. Tamazian, B.B Rao, Energy Econ., 32, 137-145 (2010)

10. S. Ullah, N. Apergis, A. Usman, M.Z. Chishti Env. Sci. and Poll Res. Inter., 27, 31892-31904 (2020)

11.A.A. Andrikopoulos, D.C. Gkountanis South-Eastern Europe J. of Econ. 2, $107-165$ (2011)

12. Allen M P Model Specification in Regression Analysis pp 166 - 170 (2007) 